\title{
La figura del monstruo en el cine de horror
}

\author{
Margarita Cuéllar Barona
}

\begin{abstract}
Horror films have approached the idea of the "other" through the figure of the monster, something or somebody that comes from unknown realms in order to generate fears and anxieties that "otherness" produces in the established order. In this article, the author explores the changes that this cinematographic recreation of "otherness" has experienced though time, and explains how in the past it usually came from unknown dimensions and now it shows aspects of our "normal" world.
\end{abstract}

\section{Horror y terror}

Cuando empecé a escribir este artículo me debatí entre hablar del cine de horror en términos de cine de terror, como se le conoce comúnmente en español, o referirme a éste como mejor me sonaba, es decir, como cine de horror. Más que un problema onomatopéyico (en inglés, lengua en la que más se ha escrito sobre el tema, se le denomina horror film), el problema para mí era uno de contenido. Entiendo el terror como una consecuencia del horror. El horror alude a lo monstruoso, lo vil, lo intangible, lo atroz, etc., mientras que el terror apunta hacia el sentimiento que sobrecoge cuando el miedo toma posesión del cuerpo impidiendo el pensamiento racional. La novelista británica Ann Radcliffe, pionera de la novela gótica, dice que el horror nace de la aprensión que sentimos frente a la oscuridad y la presencia del mal que suponemos habita en ella. ${ }^{1}$ En esta medida considero que la palabra horror es más apropiada para hablar del contenido de las películas ya que el terror se ajusta a lo que siente el espectador frente a lo monstruoso del cine de horror.

\footnotetext{
1 "Terror and Horror are so far opposite that the first expands the soul, and awakens the faculties to a high degree of life; the other contracts, freezes and nearly annibilates them (...) And where lies the difference between horror and terror, but in the uncertainty and obscurity that accompany the first, respecting the dreading evil?" (Radcliffe, 1826). Las traducciones al español fueron realizadas por la autora.
} 
Tampoco podría hablar de cine de horror sin abordar la categoría misma. En términos cinematográficos esto implicaría profundizar en el tema de los géneros cinematográficos (film genre) y lo que constituye el canon de películas que forman lo que conocemos como cine de horror. La teoría que aborda el tema está llena de contradicciones, tal como lo está la teoría que se enfrenta al estudio mismo sobre géneros cinematográficos. Mientras algunos teóricos se esmeran por agrupar las películas basándose en el vocabulario y los elementos que estas comparten, otros se esfuerzan por hacer una lectura donde prevalece el afán por determinar y descifrar la simbología y el significado de las películas con el fin de definir una línea ideológica común a cada género. ${ }^{2}$ En relación al cine de horror podríamos decir que dentro del "vocabulario" común a sus películas encontraríamos la figura del monstruo, la sangre, la muerte, las fuerzas del más allá, lo diabólico, etc. Parte de este vocabulario también incluye elementos netamente cinematográficos, como por ejemplo el uso frenético de la cámara, los planos psicológicos, la iluminación (uso de las sombras y del claroscuro), el juego con lo que no se muestra (las acciones que suceden en off), etc. Una lectura sobre su significado se acercaría más a la particular relación que se da entre estos elementos. En términos que competen al cine de horror encontraríamos que las emociones que se tejen a partir de su vocabulario (como el miedo, la ansiedad, la angustia y el suspenso), se generan en relación a un choque de fuerzas en aparente contradicción como el bien vs. el mal, lo diabólico vs. lo sagrado, la oscuridad vs. el día, etc. El monstruo juega un papel central en las películas ya que su figura es la encargada de personificar esas antinomias y por ende es el lugar donde convergen todas las ansiedades. Por otra parte, la presencia del monstruo, es decir de la otredad en su forma maligna, es la que hace de la película algo más que un mero thriller.

El cine negro (film noir) y el cine de horror son tal vez los dos géneros cinematográficos que más han estado expuestos a la interpretación psicoanalítica. En su trabajo sobre el cine de horror titulado The American Nightmare: Horror in the 70', Robin Wood, profesor de estudios de cine de la Universidad de York en Canadá y miembro fundador del colectivo editorial CineAction, acude al psicoanálisis para hacer una analogía entre éste y los sueños. Wood encuentra que en los años setenta, momento en el cual escribe la mayoría de sus textos, el carácter fantástico del cine de horror dificulta la posibilidad de elaborar discursos académicos alrededor de éste ya que se percibe como un género escapista. A través de su trabajo, Wood logra invertir esa percepción y le confiere un lugar importante dentro de los estudios de cine y los estudios culturales. El lente del psicoanálisis evidencia que más allá de ser un género fantástico, el cine de horror

\footnotetext{
${ }^{2}$ Para más documentación sobre el tema léase, entre otros, Rick Altman, 1999, Film/Genre. Londres: BFI.
} 
intenta darle forma a temas que han sido reprimidos. Wood plantea que el deseo inconsciente que emerge en los sueños es producto de una represión social que encuentra la manera de desbordarse enunciando explícitamente aquello que se desea. Tal desbordamiento funciona de manera similar en el cine de horror donde éste se presenta como una crítica puntual a la sociedad que actúa como represora. ${ }^{3}$ Para Wood, entonces, el cine de horror opera de manera similar a los sueños, en la medida en que revela temas que no pueden ser abiertamente enunciados y que han buscado diferentes maneras de aflorar. Wood argumenta que, por su carácter popular, el cine de horror podría someterse a una interpretación similar a la que hace el psicoanálisis de los sueños, ya que, al igual que éstos, revela aquello que no puede ser explícitamente citado porque ha sido desplazado del consciente individual y colectivo (Wood, 2002: 30). ${ }^{4}$

Aludiendo a la obra de Gad Horrowtiz (Basic and Surplus Repression in Psychoanalytic Theory: Frend, Reich, Marcuse), Wood identifica dos formas de represión. Por un lado llama represión básica a aquella que posibilita a los humanos vivir en sociedad y armonía porque nos permite "posponer la gratificación a través del desarrollo del pensamiento y los procesos de memoria o de la capacidad de un auto-control y de nuestro reconocimiento y consideración por otras personas". ${ }^{5}$ Por otro lado se refiere como represión surplus a aquella represión que nos limita como seres humanos y que viene de la represión ideológica impuesta por una sociedad que nos condiciona. Wood plantea que aquello que se escapa a la represión personal (básica) pasa a ser reprimido por las presiones impuestas por la sociedad (surplus). En su ensayo The American Nightmare: Horror in the 70's, el autor no sólo logra delinear la manera como el monstruo del cine de horror encarna aquello que se reprime, sino que aborda la relación ambivalente que el monstruo entabla con los espectadores. Por una parte, el monstruo representa todo aquello que no se permite ni se acepta socialmente, pero por otra su acto transgresor personifica nuestros deseos de romper con las reglas y el orden. Dice Wood que "gran parte del efecto y la fascinación por el cine del horror recae en nuestro deseo por romper con las normas que nos oprimen y que nuestro condicionamiento moral nos enseña a reverenciar". ${ }^{\circ}$

En el contexto del psicoanálisis, un concepto que resulta clave para el estudio sobre el cine de horror es el concepto del otro. Este otro no necesariamente cohabita

\footnotetext{
3 "[...] The unconscious desire that erupt in dreams and terror films are the product of social repression, and giving expression to these desires, horror therefore implies a critique of the social world that represses them" (Wood, 2002: 21)

4 "[...] Popular films, then, respond to interpretation as at once the personal dreams of their makers and the collective dreams of their audiences, the fusion made possible by the shared structures of common ideology"(Wood, 2002: 30).

5 "[...] Bound up with the ability to accept the postponement of gratification, with the development of out thought and memory processes, or our capacity for self-control, and of our recognition and consideration for other people" (Wood, 2002:24)

${ }^{6}$ "Central to the effect and fascination of horror films is their fulfillment of our nightmare wish to smash the norms that oppress us and which our moral conditioning teaches us to revere" (Wood, 2002: 32).
} 
por fuera del individuo o de la cultura, sino que es un otro que ha sido reprimido y que para poder ser repudiado y rechazado tiene que ser proyectado externamente. Wood hace referencia a los apuntes de Roland Barthes en Mitologías, donde Barthes habla sobre cómo la otredad puede ser confrontada de dos maneras: bien sea a través del rechazo y de su posible aniquilación, o transformándola, subyugándola y haciendo de ésta algo inofensivo. ${ }^{7} \mathrm{El}$ cine de horror ha sido testigo de esta confrontación a través de la figura del monstruo: ese otro que se entiende como una amenaza y el cual estamos condicionados a repudiar, confrontar, subyugar, y en el mejor de los casos aniquilar.

El conflicto en el cine de horror se genera precisamente alrededor de la figura del monstruo y la respectiva amenaza que este le represente al status quo. La contienda entre el bien y el mal, encarnada simbólicamente (en la mayoría de los casos) entre el hombre (blanco) y el mal (lo abyecto), puede entenderse como un concepto que ampara otras fuerzas en aparente oposición tales como lo sagrado y lo profano, la barbarie y la civilización, lo urbano y lo rural, el orden y el caos, la verdad y la mentira, etc. Esta lucha varía de acuerdo al monstruo y la particular amenaza que éste simbolice, razón por la cual las películas pueden abordar temas diferentes así sus tramas sean parecidas. Si analizamos el género a través del tiempo notaremos que los monstruos de principios del siglo XX no son los mismos monstruos del cine de horror de los años setenta, tal como estos no son los mismos monstruos de los años noventa. El monstruo es un espejo de las ansiedades sociales y el tema central en el cine de horror es cómo enfrentar la amenaza simbólica que representa su presencia. En esta medida, estudiar el análisis sobre la configuración del monstruo resulta interesante a la luz de la exploración del cine de horror como un espacio donde las identidades sociales entran en constante juego.

\section{El monstruo, el otro}

Ella Shohat y Robert Stam, en su libro Multiculturalismo, cine y medios de comunicación: Critica del pensamiento euro céntrico, ${ }^{8}$ se aproximan al estudio de la representación cinematográfica del otro en términos parecidos a los que la antropología ha realizado con relación a la definición de su campo y de su “objeto” de estudio. Según los autores, estas representaciones corresponden a un

"Otherness represents that which bourgeois ideology cannot recognize or accept but must deal with (as Barthes suggests in Mythologies) in one of two ways: either by rejecting it and if possible annibilating it or by rendering it safe and assimilating it" (Wood, 2002: 27).

${ }^{8}$ Stam, Robert y Ella Shohat, Unthinking Eurocentrism, Multiculturalism and the Media. Routledge, Nueva York, 2000. 
imaginario que se da en la época colonial, del cual se nutrió por muchos años el discurso antropológico. Tales imágenes, o cabe decir, tales representaciones, no sólo informan el discurso sino que lo validan con la "evidencia" de la existencia de ese otro y de su otredad. El pensamiento colonial, tal y como lo sugieren Shohat y Stam, efectuó una lectura animalizante del otro, el colonizado, al que se dibuja como una bestia salvaje de libido indócil. Este discurso, inspirado en los argumentos de la ciencia, "operó en continuidad con la zoología, la antropología, la botánica, la entomología, la biología y la medicina", y y utilizó la cámara para capturar y escrutar a los otros: sus cuerpos desnudos, su manera de vestir, las armas que portan y los materiales con los que construyen sus viviendas. ${ }^{10}$ Tal como lo sugiere Alain Corbin en su ensayo El encuentro de los cuerpos, '"La importancia que se concede al cuerpo del otro [extraño]', escribe Philippe Liotard, 'sólo se comprende en referencia a nuestra propia historia y a nuestras propias [in]certidumbres identitarias'. Las ficciones del cuerpo 'rigen un mundo imaginario que escenifica las angustias y los deseos de una colectividad'. El cuerpo colonial lo prueba a porfía" (Corbin, 2005: 182).

El cine, no del todo inocente ante el discurso colonialista, combinó (de manera conveniente) la narrativa con el espectáculo y le proporcionó a las ansiosas audiencias del primer mundo la posibilidad de experimentar las aventuras que vivían los colonos en mundos lejanos. Estas historias eran contadas desde la perspectiva del europeo, donde el nativo, ese atractivo pero a su vez repudiado nuevo otro, se convirtió en el lugar ideal en el cual proyectar las ansiedades y miedos, frente al cual también se fortalecen las identidades nacionales y los ideales de civilización. No obstante, este nuevo otro tan frecuentemente erotizado, deseado, temido, fetichizado, no se percibió como amenaza hasta que Occidente empezó a ser testigo de las migraciones de estos otros a sus propios países. Entonces, lo que alguna vez fue una fascinante y extraña cultura pierde su esencia exótica y pasa a ser una amenaza que pone en evidencia la fragilidad de las fronteras y la inevitable penetración cultural.

Edward Guerrero, profesor de Estudios de Cine y Estudios Africanos (NYU), argumenta que la construcción social y las representaciones raciales, la otredad y lo no-blanco, son procesos en permanente evolución que se expresan de manera simbólica en el cine, en especial en las alegorías y metáforas presentes en el cine de ciencia ficción y en el cine de horror. ${ }^{11}$ Guerrero señala que el monstruo se construye a partir de las represiones políticas y sociales, al igual que de los miedos,

\footnotetext{
9 “(...) Operating on a continuum with zoology, anthropology, botany, entomology, biology, and medicine," (Stam y Shohat, 2000: 106).

10 "Colonist/racist discourse renders the colonized as wild beasts in their unrestrained libidinousness, their lack of proper dress, their mud huts resembling nests and lairs” (Stam y Shohat, 2000: 137).
} 
los tabúes, las memorias y los temas que la sociedad se rehúsa a confrontar. ${ }^{12}$ Películas como Poltergeist (Tobe Hooper, 1982), por ejemplo, se nutren de los miedos que sentimos frente a la otredad y lo desconocido. La película narra la historia de una familia (blanca) cuyo hogar se convierte en el epicentro de una batalla entre sus miembros y las fuerzas del "más allá". La paz de los Freeling, una clásica familia norteamericana que vive en los suburbios, se altera cuando su hija menor es "secuestrada" por unos espíritus. La familia busca la ayuda de una parasicóloga que se comunica con el "más allá” y encuentra que los espíritus están atrapados entre dos mundos (el terrenal y el "mundo de la luz", como ellos lo llaman) y han confundido a su hija (una pequeña de cinco años de tez muy blanca y cabellos rubios) con la puerta al "mundo de la luz". Es decir, la blancura "angelical" que emana la niña los confunde y hace que estos quieran poseerla. Los espíritus están atrapados en la casa de los Freeling porque esta fue construida sobre un viejo cementerio indio. A los constructores del conjunto residencial les fue instruido mover los cuerpos pero sólo las lápidas fueron trasladadas, dejando atrapados a los espíritus sin posibilidad de ascender a su dimensión. Cabe anotar que los espíritus entablan comunicación con la niña por medio del televisor y cuando esta desaparece la familia y la parasicóloga encuentran que la única manera de comunicarse con ella es a través del aparato donde aparentemente ha quedado atrapado su cuerpo. A pesar de que la película apunta a que los verdaderos villanos son la compañía constructora que por ahorrar dinero construye encima de los cuerpos del antiguo cementerio, Poltergeist se nutre del temor a la otredad, lo desconocido y el imaginario que se crea alrededor del indígena norteamericano. Imaginario que a su vez se nutre de la representación que se hace del indio en las películas del oeste donde lo muestran como un salvaje, sin escrúpulos y semi-caníbal. ${ }^{13}$ La película también asume una posición crítica frente a la posible alienación de la televisión, al igual que frente al peligro y al poder de su contenido. Aunque el temor a la tecnología no sea el eje central de la película, no podemos dejar pasar por alto el hecho de que el televisor sea el medio por el cual los espíritus se comunican con la niña y donde esta queda atrapada. Otros filmes como Videodrome (David Cronenberg, 1983), Ringu (El anillo, Hideo Nakata, 1998) una película de horror japonesa que fue adaptada por Hollywood (The Ring, Gore Verbinski, 2002) y Demonlover

\footnotetext{
11 "(...) social construction and representation of race, otherness, and nonwhiteness is an ongoing process, working itself out in many symbolic, cinematic forms of expression, but particularly in the abundant racialized metaphors and allegories of the fantasy, sci-fi and horror genres" (Guerrero, 1993: 57).

12 "(...) The "monster" always constitutes the return of the socially or politically repressed fears of a society, those energies, memories and issues that a society refuses to deal openly with" (Guerrero, 1993: 43).

${ }^{13}$ Para más documentación sobre el tema léase, entre otros, Jacquelyn Kilpatrick, 1999, Celluloid Indians: Native Americans and Fiml, University of Nebraska Press; Janet Walker, 2001, Westerns: Films Through History, New York: Routledge.
} 
(Olivier Assayas, 2002) escenifican de manera más evidente el temor por el peligro y la alienación que promete el consumo ilimitado de televisión, el video y el Internet respectivamente, temor que ha sido explotado de manera similar por la ciencia ficción.

Películas más recientes como Wendigo (Larry Fessenden, 2001) revelan la perpetua dependencia del género cinematográfico del temor hacia la otredad. La película narra la historia de una joven familia neoyorkina (Kim, George y su hijo Miles), que sale de la ciudad a pasar una temporada en el campo. El padre sufre un desafortunado encuentro con un cazador de venados local (Otis), quien se obsesiona con la familia y empieza acosarlos. A pesar de que Wendigo, narrada a través de los ojos de Miles, parece basarse en el temor a la oscuridad, la película se construye a partir de los imaginarios sobre campo y ciudad, lo urbano y lo rural, lo civilizado y lo salvaje. Es importante rescatar que el concepto de frontera juega un papel tan importante en el cine de horror como lo hace en el cine del oeste. El concepto de frontera y sus límites, tan evidentes en Wendigo, funcionan como una metáfora de ley y orden donde todo lo que queda del otro lado es abyecto y por lo tanto se posiciona como una amenaza a las estructuras del orden social. Películas como Wendigo, Alien (Ridley Scott, 1979), The Blair Witch Project (El proyecto de la bruja de Blair, Daniel Myrick \& Eduardo Sánchez, 1999), From Dusk till Dawn (Del crepúsculo al amanecer, Robert Rodríguez, 1996), The Sbining (El resplandor, Stanley Kubrick, 1980), Carne de tu carne y La Mansión de Araucaima (Carlos Mayolo, 1983 y 1986, respectivamente) aluden a la idea del hombre "cruzando fronteras" y exponiéndose a los riesgos que esto implica. En el cine de horror la frontera separa la vida de la muerte, la locura de la cordura, la noche del día, lo normal de lo aberrado, y el monstruo es la figura que representa todo aquello que está más allá de lo permitido, de lo socialmente aceptado y realizable. Si bien las ansiedades con respecto a esos límites cambian de película en película, la función del monstruo siempre es la de alterar el orden simbólico.

El cine de horror, tal como lo enuncia Robin Wood, revela la historia de las ansiedades del siglo XX (Wood, 2002), donde el monstruo se ha convertido en el lugar dónde se proyectan todos los malestares. Para Wood, una definición básica del cine de horror podría resumirse como una serie de películas donde "la 'normalidad' es amenazada por un monstruo" (Wood, 2002: 31). Por su parte, el monstruo se conforma, entre otras cosas, en oposición a los valores que la cultura "blanca" occidental realza, tales como pureza, espiritualidad, limpieza, virtud, simpleza, felicidad, inocencia, delicadeza, feminidad, abstinencia, castidad, etc. La mujer occidental es la portadora de la mayoría de estos valores y no es sorprendente que la violación de una mujer blanca por un otro no-blanco sea 
un motivo recurrente en la ficción occidental y en el cine de horror. La violación sexual no sólo transgrede en la medida en que un no-blanco toma posesión del cuerpo de una mujer blanca, propiedad exclusiva del hombre blanco, sino que al "mancharla" lesiona los valores de pureza e inocencia inscritos en su cuerpo. Se suma a la ansiedad la amenaza a la "pureza" étnica que implicaría la descendencia de una relación inter-racial. No es coincidencia que las primeras películas de terror, o las primeras películas que hablaron de un otro-monstruoso, funcionaran bajo una dinámica dónde las mujeres blancas eran las víctimas (u objetos de deseo) de estos monstruos. Entre estos ejemplos encontramos películas como King Kong (Cooper \& Shoedsack, 1933), Nosferatu (F.W. Murnau, 1922), Drácula (Tod Browning, 1931), La bella y la bestia (de la cual hay muchas versiones que datan desde 1889 hasta la más reciente en 1991), etc., donde se evidencia la animalización de ese otro. No es coincidencia tampoco que todos estos monstruos vengan o habiten en tierras lejanas y que estén controlados por instintos salvajes.

En su libro White, Richard Dyer alude al rol que el imaginario de la raza juega sobre la estructura del mundo moderno. Dyer argumenta que la construcción de raza se hace partiendo del blanco como norma, lo que implica que la categoría blanco se posiciona como "raza humana" y lo no-blanco pasa a ser equivalente al otro. En palabras de Dyer "decir que uno trabaja o está interesado en temas de raza implica que uno hace referencia a imaginarios de raza distintos a los de la raza blanca". ${ }^{14}$ Dyer apunta también al papel que el cristianismo ha jugado en la construcción del imaginario blanco y en la noción del cuerpo. El cristianismo no sólo se convierte en la religión que Europa exporta sino en el responsable de la dualidad maniquea que se genera en torno a los imaginarios del blanco y el negro. Los colores adquieren una fuerza simbólica y connotaciones como puro vs. impuro, perfecto vs. imperfecto, sagrado vs. diabólico, etc. Esta dualidad se evidencia en el constante blanqueamiento de las figuras sagradas, en especial la de la virgen María y Jesús. El blanqueamiento está ligado a una idea de espiritualidad, superioridad, nobleza y pureza que intenta acercar ese cuerpo blanco a la divinidad.

La relación con el cuerpo juega también un papel central en la construcción del otro. La represión de los impulsos sexuales (igualmente céntrica en la doctrina cristiana) media nuestra relación con el cuerpo haciendo de éste un foco de vergüenza, pudor y tabú. Shohat y Stam hacen referencia a la manera un tanto obsesiva en que los "documentalistas etnográficos" de principios de siglo

\footnotetext{
14 “(...) That one is interested in race has come to mean that one is interested in any racial imagery other than that of white people” (Dyer, 1997: 1).
} 
XX se esmeraron por capturar los cuerpos desnudos de los otros no-blancos, particularmente los cuerpos femeninos, donde se insinuaba su incontrolable y voraz apetito sexual. Los autores argumentan que la fascinación de Occidente con estos cuerpos responde a su propia fetichización del cuerpo como algo impuro que debe ser escondido y reprimido.

La sensibilidad religiosa ha jugado un papel muy importante en la creación del imaginario del cuerpo. Corbin (2005) nos recuerda que "a los ojos de la Iglesia, la virginidad es, además de un estado definido por la integridad de la carne, es decir, por la 'abstinencia de todo acto venéreo consumado', una virtud que consiste en la 'perfecta abstinencia de toda acción voluntaria o de todo placer opuesto a la castidad (...)' Esta virtud no consiste en una disposición del cuerpo, sino del alma" (Corbin, 2005: 65). La pureza entonces viene ligada al concepto de limpieza, lo que a su vez representa la ausencia del pecado. El cuerpo blanco de la virgen María, ausente de toda mancha de pecado y cubierto por muchos velos, es el portador por excelencia de tal virtud. El poder del blanco se explica en tanto éste es comúnmente asociado con una idea de superioridad tanto moral como estética, contrario al negro, por ejemplo, que ha sido asociado con las fuerzas del mal y con lo sucio.

Barbara Creed (2002) sugiere que la construcción del monstruo está atada a viejas nociones históricas y religiosas basadas en aversiones que entienden el cuerpo como inmoral, perverso, podrido, productor de excremento y otras secreciones, decadente y potencialmente incestuoso ${ }^{15}$ Las imágenes heredadas del cristianismo promueven la idea de castigar al cuerpo como medio para purificar el alma. La figura de Jesús en la cruz, la corona de espinas, las flagelaciones de sus fieles, etc., son todas imágenes que celebran el dolor de la carne. Las flagelaciones, por ejemplo, no son más que un recurso para reprimir los deseos sexuales del cuerpo, y la necesidad de lacerarse nace de la convicción de que los "malos pensamientos" pueden ser superados si se castiga al cuerpo que los produce. En cierta medida el cristianismo celebra el cuerpo golpeado como recurso para limpiar el alma. No es coincidencia que las figuras más populares en el cine de horror sean figuras abominables que carecen de alma y habitan cuerpos descompuestos. Dentro de estas figuras encontramos vampiros u hombres lobo (cuerpos mitad humano- mitad animal, inmortales pero sin alma), zombies (muertos vivientes), demonios (ángeles caídos), fantasmas (almas en pena), momias (cuerpos descompuestos), etc. Tales figuras, en su mayoría criaturas de la noche, no sólo juegan en contra de la idea de una "mejor vida después de la

15 “(...) Grounded in ancient religious and historical notions of abjection - particularly in relation to the following religious abominations: sexual immorality, and perversion; corporeal alteration, decay and death; human sacrifice; murder; the corpse; bodily wastes; the feminine body and incest" (Creed, 2002: 69). 
muerte", central al pensamiento cristiano, sino que desafían la idea del cuerpo aporreado como recurso para purificar el alma y las pretensiones de divinidad que aseguran que sólo lo moral y lo puro tienen la capacidad de vida eterna y de regresar de entre los muertos. Reconocer la manera como el cine de horror se capitaliza del desprecio cristiano sobre el cuerpo resulta clave para entender algunos aspectos detrás de la fascinación por las películas que conforman el sub-género de horror que se conoce como splatter.

\section{El otro entre nosotros}

Splatter, que literalmente significa salpicar, es un sub-género del cine de horror al que pertenecen las películas que contienen elementos gore, es decir aquellas que tengan un alto contenido de violencia gráfica, donde la audiencia se salpica de sangre y vísceras. El término splatter fue usado por el cineasta norteamericano George Romero, director de The Night of the Living Dead y Dawn of the Dead (La noche de los muertos vivientes, 1968 y El amanecer de los muertos, 1978), dos de las películas de horror más importantes e influyentes, para describir el contenido de sus películas. Las películas splatter se caracterizan por una falta de orden y estructura narrativa en la que prevalece el interés por exhibir la vulnerabilidad del cuerpo humano y las posibilidades teatrales de su mutilación. El reguero de sangre, miembros del cuerpo cercenados y otros elementos de carácter grotesco, representan un desafío a nuestros parámetros de tolerancia, no sólo frente a la violencia de los actos sino ante la suciedad. Tal y como lo expresa Cristine Détrez en su libro La Construction Sociale du Corps, "la suciedad está ligada a lo límite, a lo que amenaza los límites tanto del cuerpo como de la sociedad, y la limpieza, aún en nuestras sociedades contemporáneas, debe tomarse como un ritual, una puesta en orden de nuestra experiencia" (Détrez, 2002: 6). La suciedad del splatter es entonces el lienzo donde se dibuja la relación maniquea que entablamos entre lo limpio y lo sucio; definición que a su vez no es más que "una aplicación de las definiciones entre lo sano y lo malsano" (Détrez, 2002: 7). Las prácticas de higiene (o falta de) son expuestas en relación con el cuerpo y su valor simbólico, y los directores de estas películas juegan tanto con los límites de las posibilidades de lo monstruoso como con los límites de tolerancia de la audiencia.

El cine splatter cuenta a su vez con un sub-género conocido como el slasher. La trama del cine slasher es siempre la misma: cuenta la(s) historia(s) de un grupo de jóvenes adolescentes (generalmente personajes fotogénicos), que son asesinados y mutilados por un psicópata enmascarado (generalmente una figura masculina). La mayoría de las veces los verdugos atacan a sus víctimas luego de que estas han tenido relaciones sexuales o consumido alcohol y/o drogas. El asesino 
nunca usa armas de fuego sino que recurre a artefactos poco convencionales como escalpelos, guillotinas, motosierras, espadas, tajaderas y otros elementos utilizados en la carnicería o en las cámaras de tortura. Si en el cine de horror clásico se evidencia una estructura maniquea donde el héroe es quien se dedica a combatir las fuerzas del mal y lo sobrenatural, el splatter (y por ende el slasher) se caracteriza por su falta de coherencia narrativa, donde prevalece el interés por mostrar escenas sangrientas. En el slasher, los autores de estas masacres pasan de ser otros habitantes de otras tierras a ser una especie de vengadores anónimos cuyo único propósito pareciera ser el de castigar y reprimir las transgresiones de los otros personajes de la película. El monstruo entonces, pasa de ser una amenaza a ser un castigador, encarnando una posición (moralista) frente a los valores que defiende. Películas como Halloween (John Carpenter, 1978), Friday the 13th (Viernes 13, Sean S. Cunningham, 1980), A Nightmare on Elm Street (Pesadilla en Elm Street, Wes Craven, 1984) y The Texas Chainsaw Massacre (La matanza de Texas, Tobe Hooper, 1974), son algunos de los títulos de las películas más famosas que cuentan historias de adolescentes que son sancionados por satisfacer los placeres del cuerpo. El asesino de la película Friday the 13th, que pasó a convertirse en una famosa serie, emprende una sangrienta persecución contra un grupo de adolescentes que vacacionan en un campo de verano. El homicida, que en la primera película resulta ser la madre de un niño que se ahogó en el lago mientras dos salvavidas tenían relaciones sexuales, mata de manera nefasta a todos los integrantes del grupo. Sin embargo, antes de matar, el asesino satisface los deseos vouyerísticos de los espectadores asesinando a sus víctimas luego de espiarlos mientras tienen relaciones sexuales. En esta medida el monstruo pasa de ser un transgresor a ser el guardián de la moral y el orden.

Otros monstruos que operan como opresores de los impulsos sexuales, son los que se apoderan de los personajes de Irena Dubrovna (Simone Simon) en la película Cat People (La mujer pantera, 1942) de Jacques Tourneur, y de Scott Howard (Michael J. Fox), el joven lobo de la comedia Teen Wolf (Aventuras de un lobo quinceañero, Rob Daniel, 1985). Cat People narra la historia de Irena, una diseñadora de modas serbia quien vive en Nueva York y que siente un gran temor por el poder de su sexualidad. Irena está convencida de que desciende de las mujeres panteras, quienes se convierten en agresivos felinos cuando sienten celos o cuando se excitan sexualmente. Por su parte, Teen Wolf narra la historia de un adolescente que descubre que su cuerpo se transforma en el de un lobo cada vez que se encuentra ante una presencia femenina que lo excita. Su padre, quien sufre la misma mutación, lo tranquiliza diciéndole que es cuestión de aprender a contener sus impulsos. A diferencia de las figuras como King Kong y Nosferatu, quienes personifican la amenaza que ese "otro" representa, los personajes de Irena 
y Scott internalizan e invierten el rol del monstruo haciendo de este un agente moralista que asume una posición represora frente al despertar de la conciencia sexual de los protagonistas. Si bien estos monstruos aún guardan rasgos animales, vemos cómo estos "otros" ya no son "otros" que habitan mundos lejanos, sino "otros" muy próximos, más humanos y ciertamente más cotidianos.

Un caso similar ocurre en la película Psycho (Psicosis, 1960) de Alfred Hitchcock. Muchos críticos están de acuerdo en que Psycho marcó un cambio en el cine de horror, no sólo porque le confiere cierta dignidad -a partir de Psycho el cine de horror entra a hacer parte de los círculos del "cine arte"-, sino porque acerca al monstruo a nuestra realidad diaria. Basada en la historia del asesino norteamericano Edward Gein, ${ }^{16}$ Psycho expone la fragilidad de las fronteras entre lo sano y lo malsano y revela que la ilusión norteamericana de haber construido una sociedad moral y segura no era más que eso: una ilusión. Al igual que los crímenes de Gein, Psycho traspone los horrores del cine del horror, antes proyectados en otros ajenos a la cultura occidental, a un contexto próximo y cotidiano. Si antes esas fronteras eran representadas por un otro que pertenecía a una realidad diferente, este nuevo monstruo rompe con los esquemas y pasa de un ser sobrenatural a ser un adolescente con crisis de identidad. Norman Bates (Anthony Perkins), el asesino de Psycho, no sólo es incapaz de controlar sus impulsos violentos sino que no está al tanto de ellos. Bates cree que la responsable de la muerte de Marion Crane (Janet Leigh) es su madre, quien lleva muerta varios años y cuyo cadáver Norman conserva en el ático de su casa. La señora Bates, el monstruo que habita dentro de Norman, es quien se encarga de reprimir los deseos sexuales de "su hijo" cada vez que éste se siente atraído por la presencia de una mujer.

A pesar de que estos monstruos (Irena, Scott y la señora Bates) parecieran estar encargados de mantener el orden, muchas de estas películas surgen como una crítica a las instituciones sociales como la familia, la escuela, el matrimonio, etc. Psycho es una de las primeras películas, sino la primera, en hablar de ruptura en el núcleo de la familia. En su lectura sobre el texto de Robin Wood, ${ }^{17}$ Tania Modleski argumenta que películas como The Texas Chainsaw Massacre se proponen en relación adversa a la sociedad y la cultura contemporánea. La película narra la

\footnotetext{
${ }^{16}$ Edward Theodor Gein fue arrestado en el año 1957 por el asesinato de Bernice Worden. Al entrar a su casa la policía descubrió que Gein no sólo había asesinado a Worden, sino que la había decapitado y descuartizado. La policía además encontró otra cantidad de pedazos de cuerpos, incluyendo varios cráneos y algunos artefactos (lámparas y camas) hechos con piel y huesos humanos. Durante su juicio Gein admitió excavar las tumbas de mujeres recientemente fallecidas que le recordaran a su madre. Luego de pasar once años en un hospital psiquiátrico, Gein fue llevado a juicio donde el juez declaró que no se le podía impartir una pena a causa de su demencia. Gein pasó el resto de sus días en el hospital psiquiátrico.
} 
historia de un grupo de jóvenes que mueren asesinados en manos de una familia de hombres semi-caníbales, que se quedaron sin empleo cuando el matadero local sustituyó su "mano de obra" por tecnología. Wood lee en la película una crítica al capitalismo en la medida que muestra una "monstruosa" familia que vive, literalmente, de otras personas. Por su parte, Dawn of the Dead narra la historia de un grupo de zombies que toma posesión de un centro comercial, acto que recoge la peor pesadilla de la crítica cultural que siempre ha expresado temor y rechazo por estos espacios que parecen alienar a sus usuarios y desproveerlos de su alma y de su voluntad. ${ }^{18}$

Si el cine de horror clásico gira en torno a la necesidad de matar al monstruo como vía para restaurar el orden, el splatter se propone romper con las estructuras de orden social y llevar a los espectadores a una tensión entre lo aceptable y lo inaceptable. En el segundo capítulo del libro Historia del cuerpo ("Dolores, sufrimientos y miserias del cuerpo"), Corbin (2005) habla de la violencia y de las masacres en el contexto de la revolución francesa y dice:

[...] lo más interesante sigue siendo referenciar y medir el sentimiento de horror frente a la escena sangrienta. Entendemos por esta expresión la rebelión del ser que provoca un sentimiento, más o menos fugitivo, de desolidarización y que convierte la masacre en espectáculo; la conciencia y el rechazo, estrechamente relacionados, de la proximidad con el animal y el monstruo; el descubrimiento terrorífico de la virtualidad innoble en sí (Corbin, 2005:206).

La tensión que se genera alrededor de la muerte, y de las diferentes maneras como ocurre, es uno de los grandes atractivos del cine de horror. Parte del gozo recae en la posibilidad de poner a prueba los límites sociales y los códigos normativos del mundo material. Esta tensión puede ser tanto traumática como satisfactoria. Tal y como lo expresa el crítico de cine Andrew Tudor, citando a Philip Brophy, "la gratificación en el cine de horror se basa en la tensión, la ansiedad, el sadismo y el masoquismo -disposición que es a la vez poco refinada y un tanto mórbida. El placer del texto está en dejarse asustar- y disfrutar del intercambio mediado por la adrenalina". ${ }^{19}$

Irónicamente, mientras algunos críticos se quejaban de la crueldad de las películas que se produjeron con mayor frecuencia a finales de los setenta y principios de los ochenta, este período también fue testigo de la hibridación

\footnotetext{
${ }^{17}$ Wood, Robin, 1979, American Nightmare: Essays on the Horror Film, Toronto: Festival of Festivals.

18 “In George Romero's Dawn of the Dead, the plot involves zombies taking over a shopping center, a scenario depicting the worst fears of the culture critics who have long envisioned the will-less, soul-less masses as zombies-like being possessed by the alienating imperative to consume" (Modleski, 1999: 695).
} 
de muchos géneros del cual salió lo que se conoce como la comedia de horror. Películas como The Rocky Horror Picture Show (Jim Sharman, 1975), Return of the Living Dead (El regreso de los muertos vivientes, Dan O'Bannon, 1985), Fright Night (La noche del espanto, Tom Holland, 1985), Nightmare on Elm Street (Pesadilla en Elm Street, Wes Craven, 1984) y más recientemente Scream (Scream: Grita antes de morir, Wes Craven, 1996) y From Dusk till Dawn (Del crepuisculo al amanecer, Robert Rodríguez, 1996), exploran los límites entre el horror y lo ridículo. Si bien es cierto que hablar de géneros híbridos apunta hacia la dificultad de definir los límites dentro de los mismos, es importante anotar que los procesos de mestizaje de los géneros responden a cambios políticos, de vanguardias artísticas y socioculturales, que enmarcan y posibilitan la reflexión sobre los modos de representación, entre otras cosas. La posibilidad del humor le confiere al cine de horror cierta libertad para observarse y burlarse de sí mismo, lo que en cierta medida le permite a los directores de horror cuestionar la manera como su cine mediaba temas como las representaciones raciales, la identidad y la otredad.

\section{Pastiche y parodia}

De los géneros cinematográficos, el cine de horror es el que más se caracteriza por tener una audiencia de culto. Como tal, sus películas cuentan con espectadores que conocen en detalle sus historias, los personajes y sus monstruos, al igual que algunos de los diálogos y secuencias más famosas. El director de cine de horror sabe y anticipa que su audiencia conoce los códigos del género y esto le posibilita jugar ampliamente con su contenido. El pastiche es un recurso al que los cineastas de horror contemporáneo acuden con frecuencia. Esto permite a los directores (guionistas y productores) repensar los códigos narrativos y parodiar sus propias respuestas a aquello que pudo ser causa de ansiedad. Al igual que muchos de sus colegas contemporáneos, el director español Alex De la Iglesia entiende la importancia del humor en la inversión de esas representaciones. Su primer largometraje Acción mutante (1993) narra la historia de un grupo terrorista integrado por una serie de personajes que tienen alguna clase de deformidad física. Viven en el exilio porque los ricos y los guapos no toleran su "fealdad". Para vengarse, arman un motín y secuestran a la hija de un famoso industrial. El día de la bestia (1995), su segundo largometraje, cuenta lo que acontece a un sacerdote español (Alex Angulo) de provincia que cree haber descifrado el día y la hora del nacimiento del anticristo. Convencido de haber sido escogido

\footnotetext{
${ }^{19}$ (...) Gratification of the contemporary Horror film is based upon tension, fear, anxiety, sadism and masochism - a disposition that is overall both tasteless and morbid. The pleasure of the text is, in fact, getting the shit scared out of you - and loving it; an exchange mediated by adrenalin" (Tudor, 1997:48).
} 
para impedir el hecho, el curita se marcha a Madrid, donde conoce a José María (Santiago Segura), un joven aficionado a la música death metal. Juntos se embarcan en la misión de encontrar el lugar donde se va a llevar a cabo el nacimiento. Ambas películas hacen uso de la parodia para enfrentar temas sensibles dentro de nuestras realidades cotidianas. Mientras Acción mutante se para como un desafío y una crítica a los estándares de belleza euro-céntricos asociados con lo blanco y la clase, El día de la bestia juega con el temor por el cambio de milenio y hace un fuerte comentario sobre los grupos de limpieza social que se han incrementado con tanto nervio en España.

Su tercer filme, Perdita Durango (1997), protagonizada por Rosie Perez y Javier Bardem, narra la historia de dos prófugos de la justicia que se enamoran y se unen para cometer crímenes. La película se desarrolla en la frontera entre México y Estados Unidos, donde Perdita conoce a su futuro amante Romeo Dolorosa. Romeo es un asaltador de bancos, traficante de drogas, sacerdote vudú, asesino a sueldo y, en ocasiones, caníbal. Los enamorados se convierten en los delincuentes más buscados de Estados Unidos pero logran evadir la ley buscando refugio al otro lado de la frontera. La película juega con los tropos de la otredad moldeando a sus personajes en los estereotipos y clichés que existen sobre lo latino. Extravagante, peligrosa, violenta, sensual, agresiva, voluptuosa, salvaje, sanguinaria y celosa, Perdita, encarnada por la puertorriqueña Rosie Perez, es una parodia de su propia latinidad. Por su parte, Romeo, sexy, indómito, fiero y descendiente de las cálidas aguas del caribe, es el amante latino por excelencia. Romeo no le teme a nada: roba bancos del otro lado de su frontera, es decir del lado estadounidense, trafica droga y secuestra adolescentes (blancos y rubios) para ofrecerlos como sacrificio en sus ceremonias de vudú, donde da rienda suelta a sus tendencias caníbales. Irónicamente estas ceremonias parecen condensar el temor que Occidente siente ante el vudú. En ellas Romeo no sólo consume cantidades enormes de cocaína, sino que le chupa la sangre a sus víctimas y se la escupe a la audiencia mientras se masturba. Fiel a la maldición literaria de su nombre, Romeo muere al final de la película. Sin embargo, Perdita no es Julieta y sobrevive para vengar la muerte de su amado. Conciente del valor irreverente de su apuesta, De la Iglesia se refiere a sus películas como comedias satánicas, lo cual apunta al tono oscuro pero irónico que las caracteriza. Lo extremo y grotesco de las imágenes que propone De la Iglesia atenúan el efecto de horror y permite que se puedan leer de manera cómica. Tales excesos no sólo le permiten invertir el efecto de sus películas sino que posibilita la parodia al género mismo y al uso que éste ha hecho de la otredad. 


\section{Finales abiertos}

El cine de horror que se produjo hasta el final de los años cincuenta se caracterizó por girar alrededor de los polos de la ciencia y de la naturaleza. El monstruo viene de fuera, su figura se alimenta del discurso colonialista y generalmente se presenta como una figura animal, del "más allá", del espacio exterior, o con poderes sobrenaturales. Durante este periodo, el monstruo parece responder a las ansiedades sociales de manera más reaccionaria y militante. La frontera entre el bien y el mal está claramente definida: el monstruo (el mal) se presenta como una amenaza y el papel del héroe (el bien) es el de combatirlo. Los espectadores pueden sentirse identificados con el héroe sin que esto les genere ambigüedad, y aunque la presencia del monstruo cause malestar, confían en la posibilidad de restaurar el orden al final de la película.

La era post Psycho marca un cambio en la noción del monstruo porque lo acerca a nuestro contexto cotidiano. La frontera entre el bien y el mal se difumina, el monstruo ya no viene de fuera sino que está entre nosotros. Más que una amenaza, este monstruo se comporta como castigador y vengador, y su figura es ambivalente en la medida en que defiende el orden pero al mismo tiempo lo ataca. Como espectadores podemos sentir ambigüedad frente a sus acciones porque no sabemos muy bien si sus víctimas son en efecto víctimas o si son culpables de las transgresiones por las cuales son "castigadas". Esa ambigüedad incomoda porque obliga a cuestionar la identificación con cualquiera de sus personajes. Psycho, por ejemplo, nos lleva inicialmente a identificarnos con Marion Crane. No obstante, esto nos resulta problemático, no sólo porque ella viene de robarle dinero a su jefe (sin motivo aparente), sino porque muere muy temprano en la película. Luego de su muerte los espectadores quedamos a la deriva y caemos en la trampa de creer que Norman está cubriendo las huellas del asesinato de su madre. Sólo hasta el final nos enteramos de que Norman es el asesino y entendemos el juego de Hitchcock al retarnos como audiencia e involucrarnos de manera directa en el universo "amoral" de la psiquis de sus protagonistas.

Como espectadores estamos acostumbrados a que las narraciones nos ofrezcan un cuerpo, un desenlace y un protagonista central con quien nos podamos identificar. Psycho juega con los procesos de identificación de los espectadores hacia el personaje negándole a sus espectadores la posibilidad de un desenlace satisfactorio. Por una parte, la narración no ofrece un cierre gratificante (final feliz en el que todo se resuelve) pero tampoco ofrece uno trágico (en el que todo sale mal y todo el mundo queda frustrado). Psycho introduce el cierre abierto que deja la posibilidad de una continuación, recurso que los cineastas de horror han usado para prolongar la ansiedad que producen 
sus películas. Sin embargo, a pesar de los aciertos técnicos o formales de la narración, la importancia de Psycho en el cine de horror radica en que marca un fin a la era del monstruo como un otro que amenaza de fuera. El momento final de la película, donde vemos a la señora Bates hablando dentro del cuerpo de Norman, es uno de los momentos más escalofriantes del cine. Sentado en la inspección de policía, con la peluca de su madre a medio poner, mira al vacío mientras oímos un monólogo interno que dice:

Es triste cuando una madre está obligada a decir cosas que pueden condenar a su propio hijo, pero no podía permitir que creyeran que yo soy capaz de asesinar. Lo más probable es que lo encierren, algo que yo misma debí haber hecho hace años. Siempre fue malo y estoy segura que les iba a decir que yo era la responsable de la muerte de esas mujeres y ese hombre, como si yo pudiera haber hecho otra cosa más que observar, como uno de sus pájaros disecados. Ellos saben que no puedo mover un dedo y no lo haré. Me quedaré aquí sentada en silencio en caso que en efecto sospechen de mí. Seguro me están observando. Pues que lo hagan. Que vean qué clase de persona soy. Ni siquiera voy a matar esa mosca. Espero que estén mirando .... ya verán. Ya verán, ya sabrán y ya dirán, "pero si esa mujer no mata una mosca". ${ }^{20}$

El monólogo que la señora Bates pronuncia dentro del cuerpo de su hijo evidencia que la frontera no sólo es más frágil sino que ha sido cruzada del todo: El otro no sólo está más cerca, está dentro de nosotros.

Irónicamente, el cine de horror siempre fue el otro cine. A pesar del interés y la fascinación que producía, tanto entre críticos como espectadores, el cine de horror no gozaba de la misma atención como lo hacían otros géneros. Sólo hasta los años ochenta logró despertar la atención de la academia gracias al creciente número de seguidores. Su aparente marginalidad disentía de la fidelidad de sus entusiastas. El culto que se genera alrededor de sus películas inspira el uso del pastiche y la parodia, lo que le concede al cine de horror la posibilidad de reflexionar sobre la manera como media la ansiedad social y sus representaciones de otredad. La parodia también le posibilita hacer una reflexión sobre su relación con la violencia de sus imágenes. Sin embargo la parodia sólo llega hasta un punto. En las comedias satánicas la audiencia no tiene la necesidad de cuestionar su papel como espectador ni la manera como consume

${ }^{20}$ Norman Bates' Mother: [in police custody, as Norman is thinking] It's sad, when a mother has to speak the words that condemn ber own son. But I couldn't allow them to believe that I would commit murder. They'll put him away now as I should have years ago. He was always bad, and in the end he intended to tell them I killed those girls and that man, as if I could do anything but just sit and stare, like one of his stuffed birds. They know I can't move a finger and I won't. I'll just sit here and be quiet, just in case they do... suspect me. They're probably watching me. Well, let them. Let them see what kind of a person I am. I'm not even going to swat that fly. I hope they are watching... they'll see. They'll see and they'll know, and they'll say, "W by, she wouldn't even harm a fly...". 
esas imágenes de violencia. El espectador no es alterado porque la película no lo interpela. Las comedias satánicas tampoco se burlan de quien las consume ni confrontan al espectador, porque no es lo que se proponen. La única película que conozco que ha intentado cuestionar el rol del espectador es Funny Games (Horas de terror, 1997), del director austriaco Michael Haneke.

Funny Games narra la historia de una familia que es asaltada por dos jóvenes que, sin motivos aparentes, los torturan en su propia casa. A lo largo de la película los verdugos se dirigen a la cámara (audiencia) haciéndole guiños y consultándole sobre cómo proceder. Haneke, maestro en el arte de la provocación, se propone involucrar al espectador desprevenido y hacerlo conciente del papel que juega en la producción de las imágenes que está viendo. Para Haneke la pregunta no es cómo mostrar la violencia, sino cómo mostrarle al espectador el rol que juega, desde su silla, en la producción de esas imágenes. En esta medida Haneke logra sacar al monstruo de la pantalla y trasponerlo en la audiencia que juega un rol activo en la tortura de la familia. En Funny Games, y para Haneke, el vouyerismo tiene un costo moral. Sin embargo, aunque la película se proponga como una crítica a la violencia mediante el cuestionamiento del rol, aparentemente pasivo, del espectador, no logra escaparse a la brutalidad que caracteriza las imágenes del cine de horror. Funny Games pretende ser un reto a los excesos violentos en que cae mucho del cine que se produce en la actualidad, pero termina siendo aún más perverso que aquello que se propone desafiar.

Mi posición ante el cine de horror es tan ambigua como la del espectador que no logra encontrar con quién identificarse. Entiendo la complejidad y la riqueza de sus metáforas y alegorías. Riqueza que ha sido explorada en gran extensión por la crítica feminista, ${ }^{21}$ por ejemplo, que encuentra potencial en la exploración del rol de la mujer en el cine de horror. Sin embargo, a pesar de que entiendo el capital de su contenido, no logro escaparme al horror y el terror que producen sus imágenes. Con respecto a la mayoría de las películas mencionadas en este artículo, no podría decir que las recomiendo, sólo puedo sugerir que las vean a su discreción.

\section{Bibliografía}

- Altman, Rick. 1999, Film/Genre, Londres: BFI.

- Braudy, Leo y Marshal Cohen (ed), 1999, Film Theory and Criticism: Introductory Readings, Nueva York: Oxford University Press.

\footnotetext{
${ }^{21}$ Léase Creed, Modleski y Williams.
} 
- Browne, Nick, (ed), 1998, Refiguring American Film Genres: History and Theory, Berkeley: University of California Press.

- Corbin, Alain, Jean-Jacques Courtine y Georges Vigarello (dirs), 2005, Historia del cuerpo: De la revolución francesa a la gran guerra. V.2, Taurus Ediciones: Madrid.

- Corbin, Alain, 2005, "El encuentro de los cuerpos", en: Crobin, Courtine y Vigarello (dirs.), Historia del cuerpo: De la revolución francesa a la gran guerra, V.2, Taurus Ediciones: Madrid.

- Corbin, Alain, 2005. "Dolores y sufrimientos y miserias del cuerpo" Crobin, Courtine y Vigarello (dirs.), Historia del cuerpo: De la revolución francesa a la gran guerra, V.2, Taurus Ediciones: Madrid.

- Corbin, Alain, 2005, "El dominio de la religión”, en: Crobin, Courtine y Vigarello (dirs.), Historia del cuerpo: De la revolución francesa a la gran guerra, V.2, Taurus Ediciones: Madrid.

- Creed, Barbara, 2002, "Horror and the Monstrous-Feminine: An Imaginary Abjection", en: Jancovich, Mark (ed.), Horror. The Film Reader, Londres: Routledge.

- Detréz, Christine. 2002. La construction Sociale du Corps. Paris: Editions du Seuil. (Traducción del numeral 2 de la tercera parte: "Los Usos Sociales y Culturales del Cuerpo", por Maria del Pilar Perdomo Giraldo).

- Dyer, Richard, 1997, White, Londres: Routledge.

- Guerrero Edward, 1993, Framing Blackness. The African American Image in Film, Philadelphia: Temple UP.

- Jancovich, Mark, 2002, Horror. The Film Reader, Londres: Routledge.

- Modleski, Tania. 1999. "The Terror of Pleasure: The Contemporary Horror Film and Postmodern Theory", en: Braudy y Cohen (eds.), Film Theory and Criticism: Introductory Readings, Nueva York: Oxford University Press.

- Radcliffe, Anne, 1826. "On the Supernatural in Poetry", New Monthly Magazine, vol. 16.

- Russell, David, 1998, "Monster Roundup: Reintegrating the Horror Genre", en Browne, Nick (ed.), Refiguring American Film Genres: History and Theory, Berkeley: University of California Press.

- Stam, Robert y Ella Sohat, 2000, Unthinking Eurocentrism. Multiculturalism and the Media, Nueva York: Routledge.

- Tudor, Andrew, 2002, "Why Horror? The Peculiar Pleasures of a 
Popular Genre", en: Jancovich, Mark (ed.), Horror. The Film Reader, Londres: Routledge.

- Williams, Linda, 2002 "When the Woman Looks", en: Jancovich, Mark (ed.), Horror. The Film Reader, Londres: Routledge.

- Williams, Linda, 1999, "Film Bodies: Gender, Genre and Excess", en: Braudy y Cohen (eds.), Film Theory and Criticism: Introductory Readings, Nueva York: Oxford University Press.

- Wood, Robin, 2002, "The American Nightmare: Horror in the 70's", en: Jancovich, Mark (ed.), Horror. The Film Reader, Londres: Routledge. 